\title{
MOBILE TEST STAND VALIDATION FOR MEASURING FRICTION COEFFICIENT OF CARRYING ROPE WITH FRICTION LINING
}

\author{
Michał STAWOWIAK, Marcel ŻOŁNIERZ \\ Silesian University of Technology
}

\begin{abstract}
:
The article presents the problem of friction between the rope and the friction liner of a mining hoist very important for the safety of human transport. The friction linings approved for use in the Polish mining industry and their basic mechanical properties are presented. Laboratory and operational methods of friction feedback are described. This article presents an innovative mobile research stand developed at the Department of Mining Mechanization and Robotisation. The mobile test stand validation was presented.
\end{abstract}

Key words: mining hoist, friction coupling, caring rope, friction layer

\section{INTRODUCTION}

In underground mining, various rope transport devices are used. The most important and basic equipment of rope transport can be classified as:

- mining lifts - vertical transport in the shafts Fig. 1,

- cable-railways suspended or rope or rope chair.

Mining systems use different arrangements of their solutions. One of the divisions refers to hoisting devices with machines located on the frame or the tower, and the other is for hoisting devices without or with an equalizing rope. In the national mining industry, the length of the lifts currently reaches about $1050 \mathrm{~m}$.

In the mining industry the glass has reached a depth of $1000 \mathrm{~m}$ and more meters, resulting in the increase of the length of the ropes and compensating L. By assuming, for example, a four-roll friction drive with a maximum number of balancing cables of 4 pieces and a length of $1100 \mathrm{~m}$ in the lift we have $8800 \mathrm{~m}$ ropes. In the deep mines of South Africa, where four-roller thrusters with a friction drive reach a depth of $2000 \mathrm{~m}$, with the number of ropes 4 , the total length of the ropes is $16000 \mathrm{~m}$. In Blair's twodrum lifts, which are currently used as single-ended lifts in 3600 depth shafts The length of the supporting ropes (4 in total) is $14400 \mathrm{~m}$. It is obvious that in the mining hoists, the durability of the ropes is attained. One of the directions of development of high durability ropes is corrosion protection.

Steel ropes are lubricated during:

- rope production - basic lubrication,

- during rope operation - supplementary lubrication (rope lubrication) or preservative $[10,16]$.

The effect of the corrosion of the shaft environment on the durability of the rope ropes is obvious therefore the proper lubrication of ropes during their manufacture and lubrication during operation is extremely important $[6,13]$.

The type of grease used for rope production and their relubrication during operation depends on the type of drive of the lifting machine. Other lubricants are used for ropes intended for machines with winding drums and others for machines with friction motors [5].

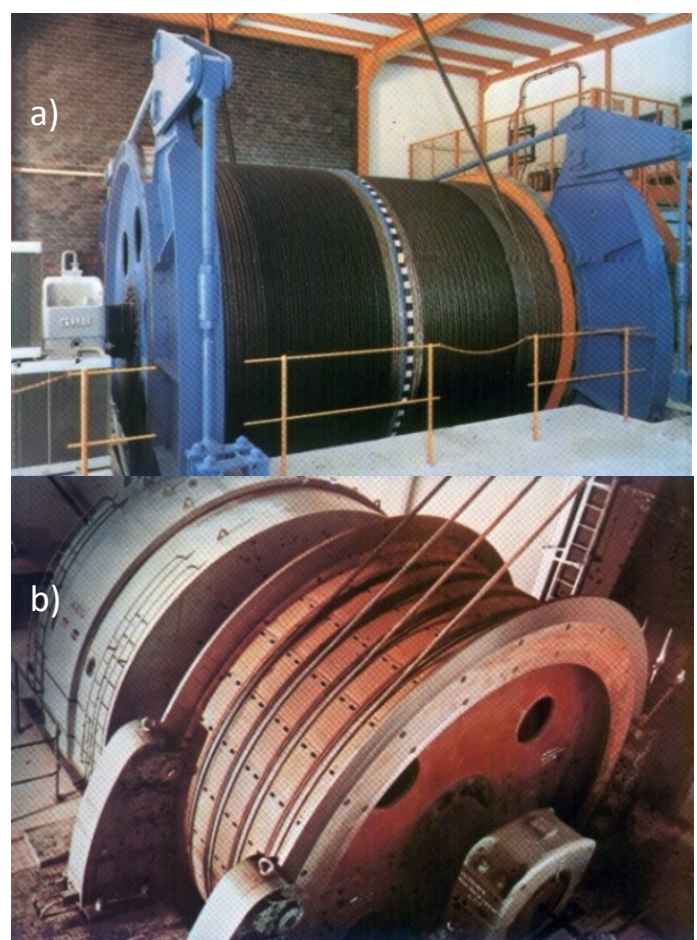

Fig. 1 View of hoisting machines: $a$ - with drum drive, $b$ - with friction drive Source: [6]. 
In rolls with winding drums, the lubrication and relieving of the lifting ropes does not create any operational problems (in this type of drives there are no rope slides). In friction friction hoists there is a risk of rope slippage, therefore lubricants for ropes used in friction frictions must ensure the behavior of the calculated friction coefficient between rope and liner $\mu \geq 0,25$. The magnitude of this coefficient of friction is influenced by the following factors $[2,3,4,5,6,7,8,9]$ :

- type of grease,

- the amount of grease in the line and on the line,

- type of friction linings,

- liner operating conditions: dry, wet glass.

\section{THE CASE OF THE CIRCIUT BREAKER ON THE DRIVE WHEEL}

The analysis of literature shows that in the analysis of frictional coupling the following factors [4] should be noted:

- type of drive,

- the coefficient of friction between the steel rope and the lining,

- material type and geometric shape of the groove of the liner,

- rope construction,

rope lubrication during production,

how to lubricate the rope during operation,

types of used lubricants,

rope reliability coefficient before slipping,

acceleration and deceleration allowed and critical,

braking delays transmitted by safety brakes,

degree of static imbalance of the lift,

the lifting capacity and its type,

the impact of rope wheels in the extracts with the machine on the stump and the imprint wheels in the elevator machines located on the tower,

- taking into account the elasticity of the ropes,

- lowering the load in the two-vessel extracts,

selection of braking torques.

The principle of the propeller-rope drive is described in Euler-Eytelwein's formula (1) [11, 17], with Fig. 2.

$$
\frac{S_{n}}{S_{z}}=e^{\mu \propto}
$$

where:

$\mathrm{S}_{n}-$ force in the stretcher rope, $\mathrm{N}$,

$\mathrm{S}_{z}$ - force in the coiling rope, $\mathrm{N}$,

$e$ - basis of natural logarithm,

$\mu$-coefficient of friction between rope and friction liner,

$\alpha$-angle of the wheel wrap around the rope, deg.

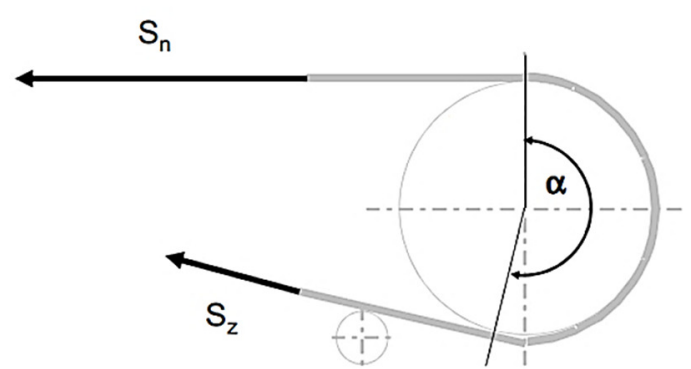

Fig. 2 Principle of operation of the friction-liner drive: $S_{n}, S_{z}$-force in the runaway rope Source: [15].
An important parameter of Euler's formula is the friction coefficient $\mu$ between the rope and the wheel liner. This is referred to as the friction coefficient.

\section{THE COEFFICIENT OF FRICTION FEEDBACK}

The coefficient of friction feedback depends on many parameters. In friction-driven extractors used in mining we use the rope reliability coefficient before static or dynamic slip. Both of these definitions include the coefficient of friction $\mu$. Practically, the rope reliability factor is expressed by the critical and acceptable acceleration and deceleration of the lifting machine. Their choice allows the elimination of slip ropes [3].

In fact, we can distinguish much more types of friction coefficients. Considering the relative state of work (state of rest, state of motion) of friction pair steel rope liner and the conditions that this condition cause we can distinguish [3]:

- static coefficient of friction $\mu_{s}$ - characteristic for calm state when rope and liner are in absolute calm. Its size does not really matter for friction coupling, which can only be checked against the operating factor,

- kinetic (operating) coefficient of friction $\mu_{k}$ - characteristic for the normal operating state, when rope and liner are in "relative calm". This "relative calm" is the result of a common rope movement and linings (creep rope) determined by the operating speed of the lift. Its value depends on the creep speed and the operating speed of the lift. This factor is critical for the safe operation of the propulsion system,

- friction coefficient $\mu_{\mathrm{g}}$ - characteristic for operating conditions when it passes from the apparently relative state to the relative state of rope movement after the liner. Its size does not include any more information, but this factor is important because it causes an emergency condition of the exhaust system,

- dynamic coefficient of friction $\mu_{d}$ - characteristic of conditions arising after an emergency, when a high relative velocity between the rope and the lining.

\section{LABORATORY RESEARCH OF THE COEFFICIENT OF FRIC- TION FEEDBACK}

In order to obtain the permission to use the wheel liner, it is necessary to carry out laboratory tests on friction coefficient $\mu$ of friction pair steel rope - liner. According to the Regulation of the Council of Ministers of 30 April 2004 on the admission of products for use in mining plants, the liner should provide a friction coupling with a bearing rope with a coefficient greater than or equal to 0.25 [14]. Due to the lack of an international standard for friction coefficient testing, each country carrying out such tests has developed its own test conditions [6]. Test sites, due to their type of construction, can be divided into those in which the friction coupling is tested [15]:

a) on the straight line of the rope:

- pulled wire rope without voltage (Fig. 3),

sliding jaws with lining on the stretched line (Fig. 4), pulling the stretched rope through immobilized jaws with lining, 
b) on the model wheel:

- pulling the rope on the lining of the immobilized wheel (Fig. 5),

- pulling the rope around the wheel with the liner by means of hydraulic cylinders (Fig. 6),

- turn the wheel with the liner against the loaded rope,

pulling the rope on the wheel with the lining with the second drive wheel.

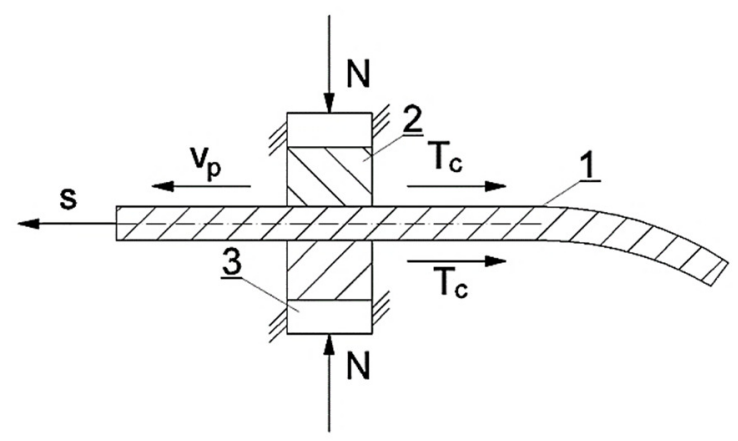

Fig. 3 Pulling the line without tension:

1 - tested rope, 2 - tested liner, 3 -jaws for liner,

4-device housin

Source: [15].

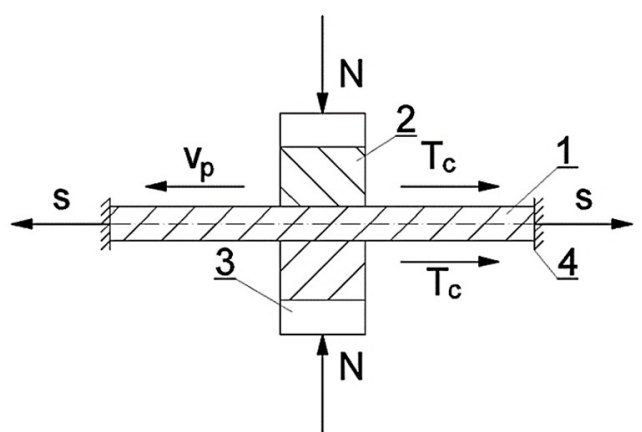

Fig. 4 Sliding the jaw with the lining on the stretched line: 1 -tested line, 2 - tested carpeting, 3 -jaws for carpeting, 4-device casing Source: [15].

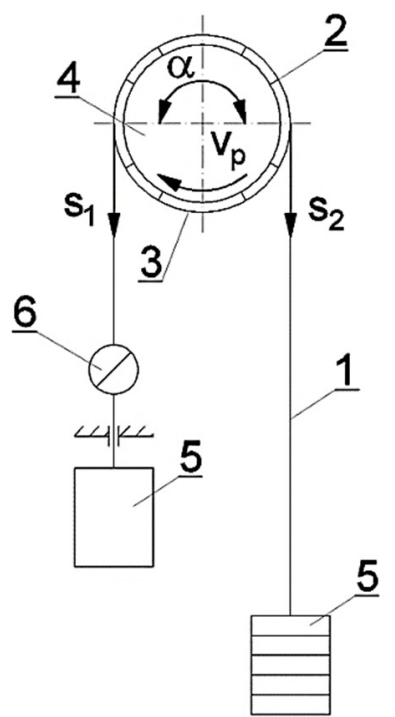

Fig. 5 Pulling the rope around the wheel of the immobilized wheel

1-tested rope, 2 - tested liner, 3 - groove for liner, 4-wheel with liner, 5-tensioning weight, 6 -force gauge

Source: [15].

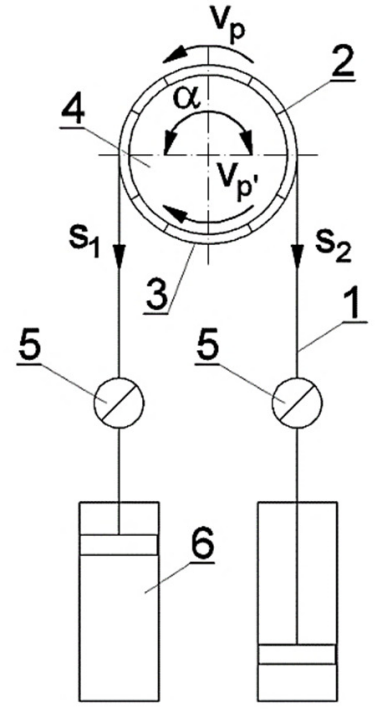

Fig. 6 Pulling the rope around the wheel with the liner by means of hydraulic cylinders

1 - tested rope, 2 - tested liner, 3 - groove for liner, 4-wheel with liner, 5 -force gauges, 6 - hydraulic cylinders

Source: [15].

\section{CALCULATION OF THE COEFFICIENT OF FRICTION FEED- BACK DURING OPERATION}

The literature review shows that the following methods have been used to determine friction coefficient in operating conditions [5]:

1) Determination of the friction coefficient by rotating the wheel or drum relative to the rope branch of the coiled rope while simultaneously measuring the forces (with oscillation) in the rising and falling branches of the rope. The coefficient of friction is calculated from the relation:

$$
\mu=\frac{1}{\alpha} \ln \frac{S_{1}}{S_{2}}
$$

where:

$\alpha$ - angle of wrapping the wheel full of rope, rad, $S_{1}, S_{2}-$ measured forces in the branch of the rising and falling rope, $(\mathrm{kN})$ when the rope is slipping relative to the wheel liner.

2) Determination of friction coefficient in case of slipping rope with lining on the measuring path (with oscillograph recording) of the delay parameters during braking of the lifting machine during emergency braking of the lifting machine when lowering the loaded lifting vessel. The coupling factor is calculated from the dependence:

$$
\mu=\frac{1}{\propto} \ln \left(\frac{S_{2}+M_{2} \cdot b}{S_{1}-M_{1} \cdot b}\right)
$$

where:

$S_{1}, S_{2}$ - measured forces in the branch of the rising and falling rope, $(\mathrm{kN})$ when the rope is slipping relative to the wheel liner,

$M_{1}, M_{2}$ - measured mass in the branch of the rising and falling rope, $(\mathrm{kg})$ at the moment of slipping of the rope relative to the wheel liner,

$b$ - measured maximum braking delay of the lifting machine, $\mathrm{m} / \mathrm{s}^{2}$. 
3) Rotary wheel method with one propeller shaft supported and engine arm current measurement (KWK "Krupiński" method), Fig. 7.

4) The method of determining the forces in the rope branches by the specified groove groove of the liner (VNIIGM method), used only in multi-rolls.

5) UPT device of KWK "Pniówek" construction.

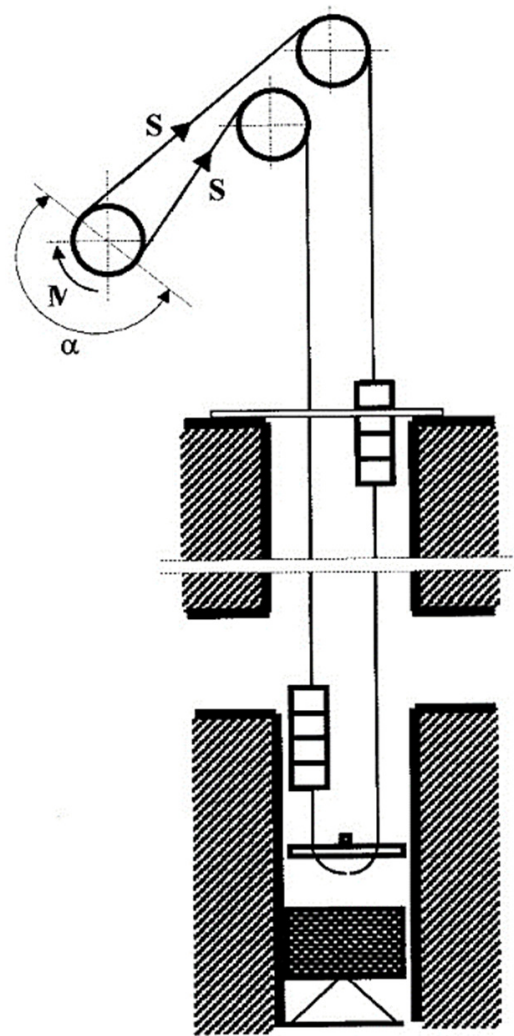

Fig. 7 Scheme of the hoisting gear with impeller to determine the friction coupling using the KWK "Krupiński" Source: [3].

The method of the "Pniówek" mine, as refined by the Institute of Mechanization of Mining, is presented in Fig. 8 [1]. Schematically some methods of evaluation of friction coupling using UPSC (Urządzenie Pomiarowe Sprzężenia Ciernego) are shown in Fig. 9.

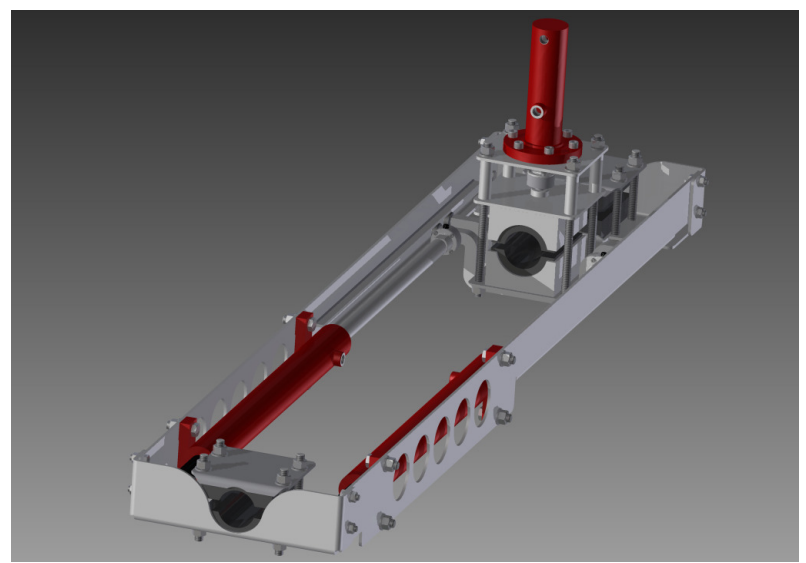

Fig. 8 Model of UPT device developed by the Institute of Mechanized Mining, Silesian University of Technology a)

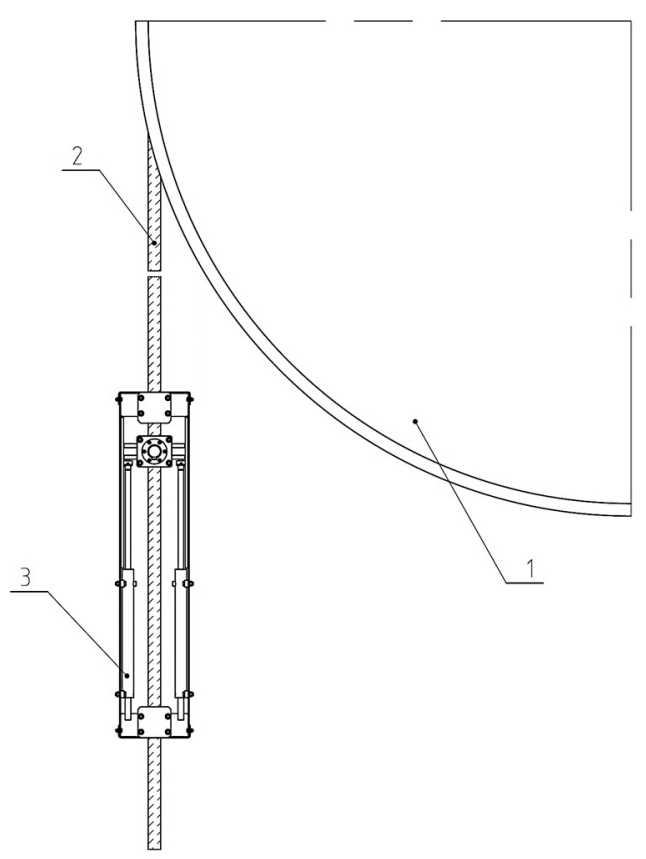

b)

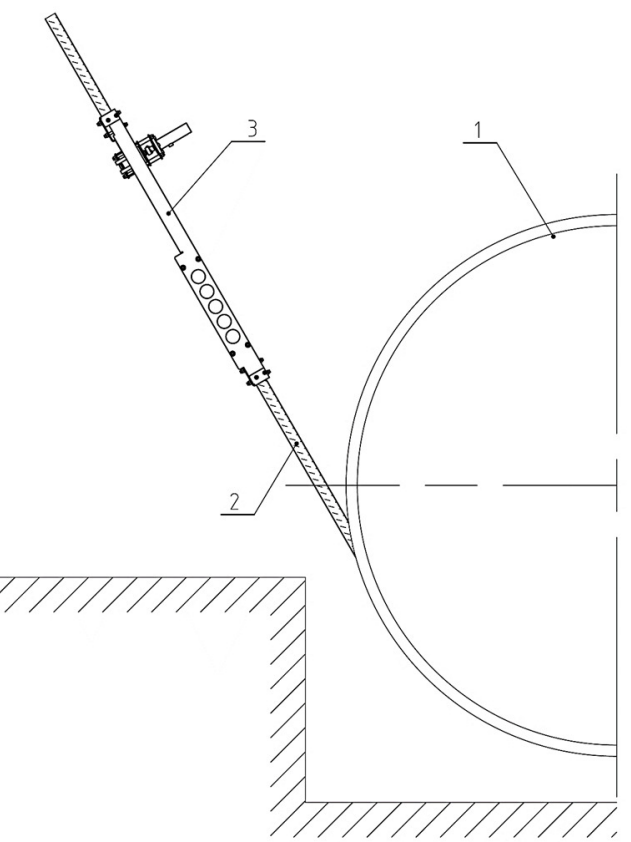

Fig. 9 The way of assembling the UPSC device in the case of the winding machine

a) on the tower, b) in the framework: 1 - winding machine pulley, 2 - rope, 3 - UPSC device

\section{UPSC DEVICE VALIDATION}

Initial tests of the frictional feedback coefficient were made at a stationary station located in the Department of Mechanization and Robotic Mining of the Silesian University of Technology. For this purpose, the head of the stationary station was disassembled to obtain adequate space for the mobile station. A Becorit K22 liner was installed in the mobile device jaws for which the measurement of the frictional feedback coefficient with the steel wire was carried out. Identical measurements of the frictional feedback coefficient for the same friction pair were made at a stationary position. Fig. 10 presents a diagram of a stationary station for testing the frictional engage- 
ment of a wire rope with a friction liner and its photograph in Fig. 11. In contrast, in Fig. 12, a picture of the rope with a cross-section.

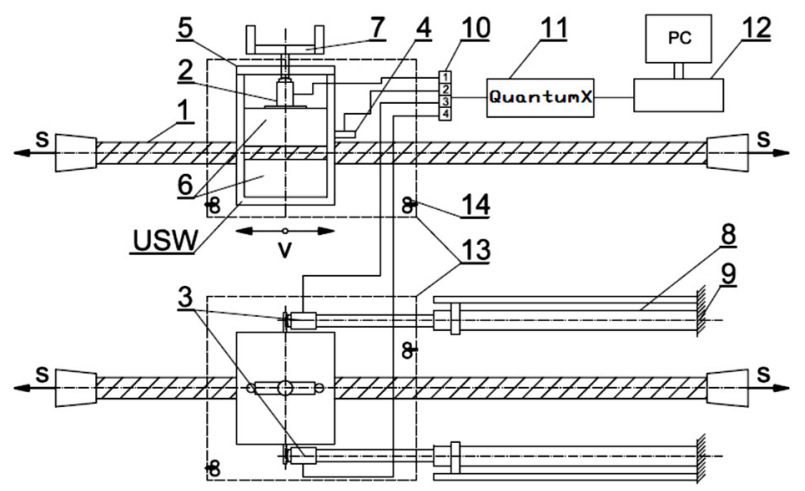

Fig. 10 The cover of the mobile clamp, 1 - rope, 2 - liner; The basic elements of the station are:

1 - steel wire, 2- tensometric pressure sensor, 3 - strain gauge friction sensor, 4 - temperature sensor, 5 - compression device, 6 - jaws with lining, 7 - screw clamp mechanism, 8 - hydraulic cylinders, 9 - housing of a horizontal testing machine, 10 - terminal block, 11 - measuring transducer (QuantumX MX840A), 12 - PC computer, 13 - thermal chamber, 14 - heater

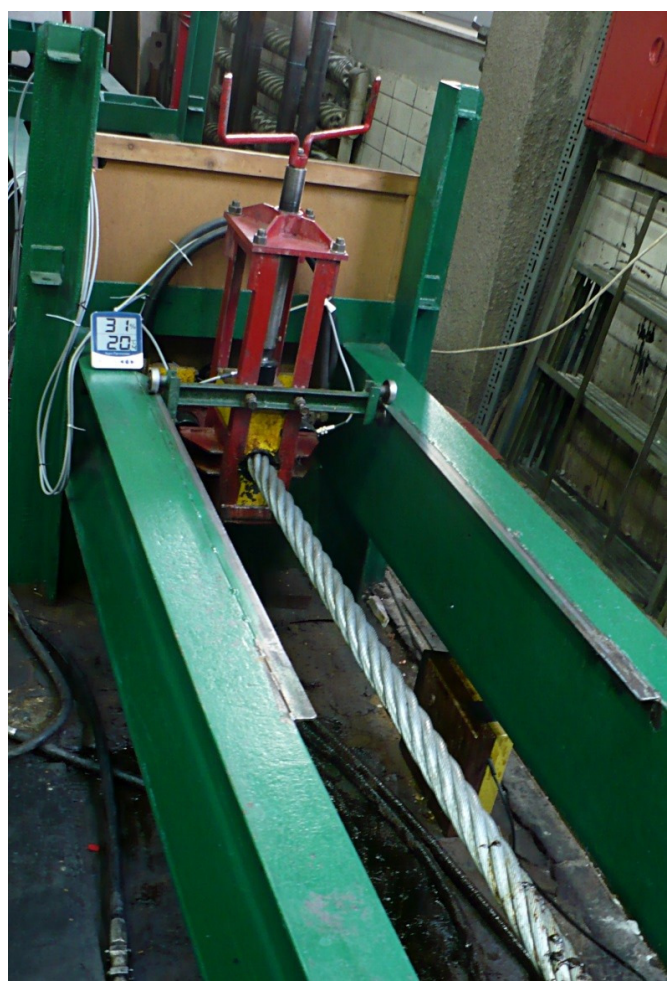

Fig. 11 Mobile terminal cover, 1 - rope, 2 -carpeting Source: [9].

The research involved the use of coiled steel rope with a real (measured) diameter of $50 \mathrm{~mm}$, with a surface contact of $6 \times \mathrm{K} 41 \mathrm{WS}+\mathrm{FC}$ wires (nominal diameter $47 \mathrm{~mm}$ ) manufactured by Teufelberger Seil $\mathrm{GmbH}$ as shown in Figure 12 .
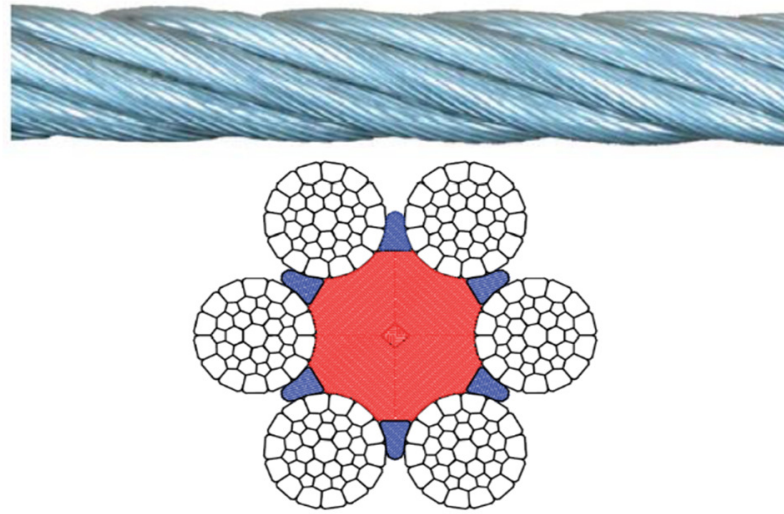

Fig. 12 Extract rope of the compact coil construction type $6 \times$ K41WS + FC by Teufelberger Seil GmbH Source: [18].

The Becorit K22 liner shown in Fig. 13 was used as a friction material.

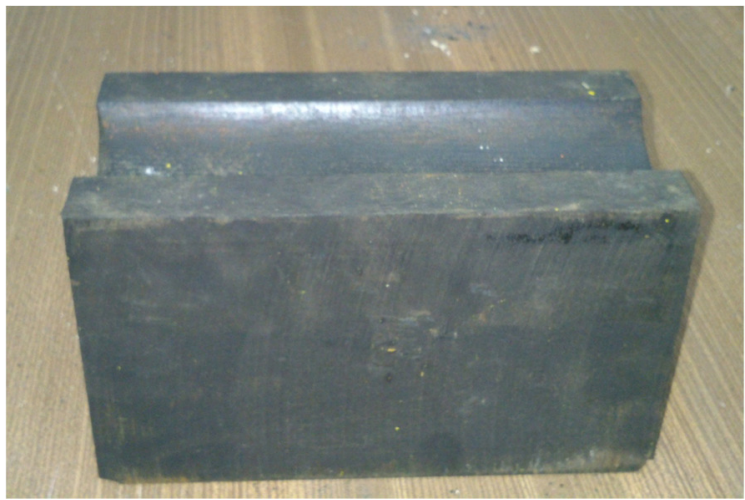

Fig. 13 Becorit $K 22$ lining

Source: [9].

Both stationary and mobile station tests were performed based on DIN 21258 [12]. During each test, the computerized measurement system recorded instantaneous values: friction forces, clamping forces of friction liner samples to the rope, and the time of testing with a frequency of $20 \mathrm{~Hz}$. Friction feedback tests were performed to a limited extent, ie only for dry friction pair.

Sample waveforms recorded on a stationary test bench are shown in Fig. 14 and 15.

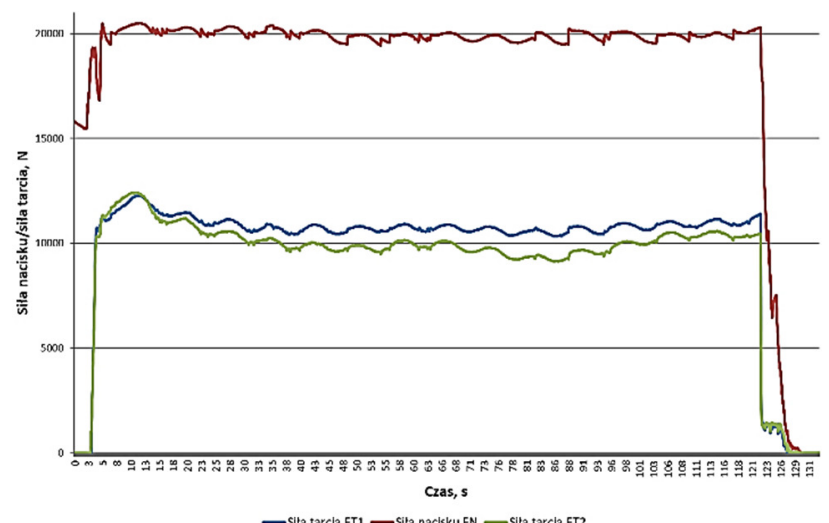

Fig. 14 The course of recorded forces at a stationary position, measurement 1 


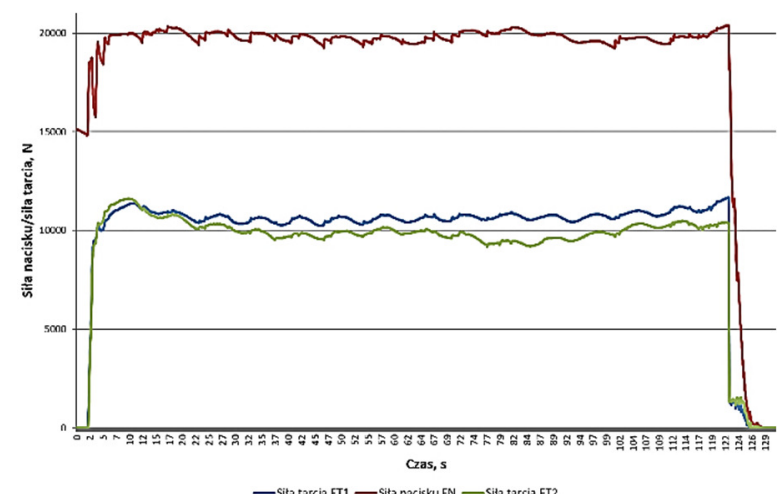

Fig. 15. The course of recorded forces at a stationary position, measurement 2

Fig. 16 and 17 show the course of pressure and friction forces for a mobile station.

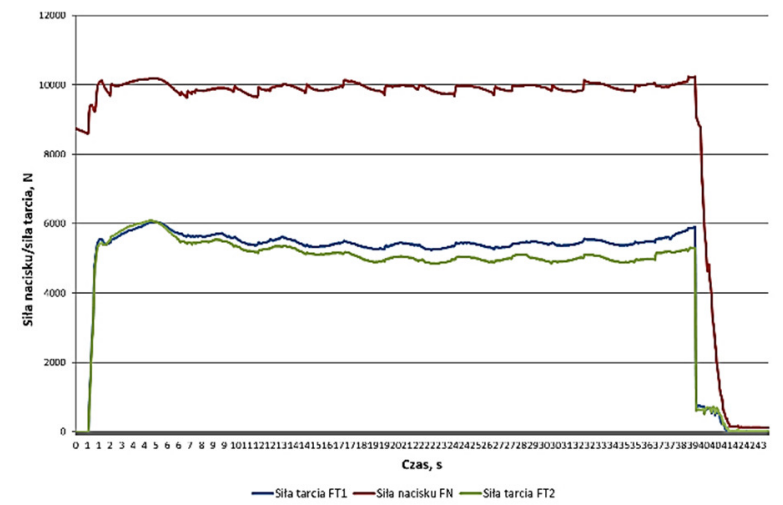

Fig. 16 The course of registered forces on the UPSC mobile station, measurement 1

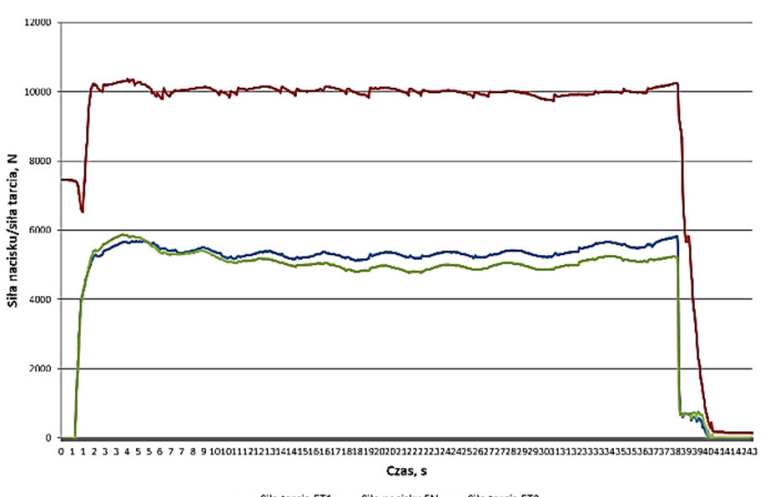

Fig. 17 The course of registered forces on the UPSC mobile station, measurement 2

The average value of the kinetic friction coefficient for a single test was calculated based on the instantaneous values of the kinetic friction force $F_{T 1}$ and $F_{T 2}$ and the value of the $F_{N}$ pressing force to the rope (Figure 18) registered by a computer measuring system according to the dependence (4) [9].

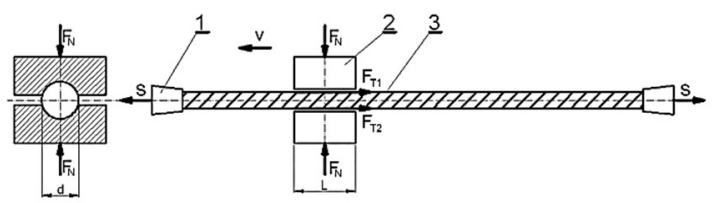

Fig. 18 Model of rope and liner cooperation adopted for laboratory tests:

1 - conical sleeves, 2 - liner, 3 - rope

Source: $[9,13]$.

$$
\overline{\mu_{k}}=\frac{\overline{F_{T}}}{F_{N}}=\frac{F_{T 1}+F_{T 2}}{2 F_{N}}
$$

where:

$\bar{\mu}_{k}$ - the average value of the kinetic friction coefficient, $F_{N}$ - clamping force of the samples to the wire rope, $\mathrm{N}$,

$\bar{F}_{T}$ - the average kinetic friction force, $\mathrm{N}$,

$F_{T 1}, F_{T 2}-$ value of the kinetic friction force, $\mathrm{N}$.

In accordance with the requirements of DIN 21258, each measurement should be repeated six times and as the final value, take the mean value of the coefficient of friction from five measurements [18]. The liner pressure per rope was calculated according to the formula [11]:

$$
p=\frac{F_{N}}{A}=\frac{F_{N}}{L \cdot d}
$$

where:

$p$ - unit pressure of the liner on the rope, $\mathrm{MPa}$,

$F_{N}$ - clamping force of the samples to the wire rope, N,

$L-$ the length of the lining test section, $\mathrm{mm}$,

$d$-diameter of the rope, $\mathrm{mm}$.

If it is necessary to obtain the required pressure of the liner on the rope, that is $2.0 \mathrm{MPa}$, with the following data: the length of the liner $L$ in one jaw we get the required forces $F_{N}$ for the rope [9]: $F_{N}=p \cdot L \cdot d$

The relationship between the pressure force of the liner and the momentary friction force is determined by the formula [9]:

$$
\overline{F_{T}}=k \cdot \mu \cdot F_{N}, N
$$

where:

$\mu$-coefficient of friction between the rope and the wheel liner,

$k$ - number of rubbing surfaces.

Kinetic coefficient of friction for two friction surfaces $(k=2)$ was calculated from dependence [9]:

$$
\overline{\mu_{k}}=\frac{\overline{F_{T}}}{k \cdot F_{N}}
$$

where:

$\bar{\mu}_{k}$ - average value of the kinetic friction coefficient.

The average (from a series of tests) value of the kinetic friction coefficient was calculated according to the formula 8 [12].

$$
\overline{\mu_{s r}}=\frac{1}{n} \sum_{i=1}^{n} \overline{\mu_{k}}
$$

where:

$\bar{\mu}_{s r}$ - average value of kinetic friction coefficient from a series of tests,

$n$ - number of measurements, $\mathrm{n}=5$.

The determined frictional feedback coefficients at the stationary and mobile station are summarized in Table 1.

Table 1

The value of frictional coupling determined on the stationary and mobile station

\begin{tabular}{lcc}
\hline Measurement & Stationary stand & Mobile stand UPSC \\
\hline $\mathbf{1}$ & 0.519 & 0.511 \\
$\mathbf{2}$ & 0.529 & 0.518 \\
$\mathbf{3}$ & 0.526 & 0.523 \\
$\mathbf{4}$ & 0.516 & 0.521 \\
$\mathbf{5}$ & 0.520 & 0.519 \\
Average value $\overline{\boldsymbol{\mu}}_{\boldsymbol{s r}}$ & $\mathbf{0 . 5 2 2}$ & $\mathbf{0 . 5 1 8}$ \\
\hline
\end{tabular}


Based on data from Table 1, the relative error of the determined frictional feedback factor on the mobile device was calculated with reference to the determined frictional feedback coefficient at the stationary position. The calculated relative error is $0.8 \%$, which indicates the right approach in the implementation of the project assumptions of the mobile test stand and the adopted test method. For the final verification of the test procedure, it is necessary to perform a series of tests for various types of friction linings and friction pair conditions.

\section{SUMMARY AND CONCLUSIONS}

The presented issue related to the evaluation of friction feedback is extremely important for ensuring safe operation of the shaft hoist and especially during the transport of the crew. Therefore, it is extremely important to correctly determine the value of the frictional feedback coefficient using the available test methods, especially when it concerns the supplementary lifting of the lifting ropes because the long-standing practice of its use during operation has demonstrated the desirability of its use. Supplementary lubrication has contributed not only to the increase of durability of ropes but also to the increase in the safety of their operation by eliminating or diminishing the effect of corrosion on the condition of ropes. It should be noted that relubrication of lifting ropes during their exploitation in Poland is getting more and more popular and is economically justified. An important aspect of the evaluation of the frictional feedback condition are measurements directly on the hoisting device giving information for a specific friction pair under conditions similar to the operating conditions. These tests involve the exclusion of the device from operation for the time of measurement and with a significant risk for the persons performing it. Therefore, a mobile research device has been designed and patented combining the above methods of assessing the frictional feedback condition of the friction pair in question. The device allows for a quick and direct measurement of the coefficient of friction and significantly reduces the time of shutting off the machine from the movement.

Based on the completed BK work, the following conclusions can be drawn:

1. The basic and also decisive for the safety of mining friction drive shaft hoists is the fulfillment of the dependence described in the Euler formula (1). Its key component is the frictional feedback factor $\mu$.

2. The UPSC device allows you to determine the frictional feedback coefficient directly at the workplace in a short time, involving a small number of employees.

3. The weight of the device (about $105 \mathrm{~kg}$ with the hydraulic unit) and the modular structure enable quick assembly on the measuring stand.

4. The simple design of the device ensures trouble-free operation.

5. The use of force transducers in the UPSC device allows for precise reading of the value of the pressure force on the liner and friction forces, which enables very accurate determination of the frictional feedback coefficient between the carrier rope and the friction lining.
6. The applied measurement system enables the registration and visualization of measured quantities in real time, in a wide range of sampling with simultaneous archiving, giving the possibility of creating databases for a specific case of a winding machine.

7. The UPSC device can be used in a wide range of rope diameters (from 20 to $60 \mathrm{~mm}$ ) while ensuring a constant unit pressure between the rope and the friction lining, which is its important functional advantage.

8. The relative error of the mean frictional feedback coefficient at the mobile station to the ratio determined at the stationary standpoint is $0.8 \%$, which indicates the correctness of the adopted test procedure for the built-up prototype of the test device.

Summarizing the tasks performed at work, it should be noted that a series of friction feedback measurements should be performed for different friction pair states to have a full set of tests for the final evaluation of the proposed test method for the designed mobile friction coupling measurement device.

\section{REFERENCES}

[1] J. Brodny, M. Żołnierz. A measuring system for determining the frictional feedback coefficient, Patent No. P.407885, Gliwice: Silesian University of Technology, 2016.

[2] A. Carbogno. Tests of the coefficient of friction between different linings and the steel cable greased with Elaskon greases, Zabrze: International Seminar on State of the art in the field of corrosion protection and lubrication of wire ropes, Elakson Sachsen, 2001.

[3] A. Carbogno. Evaluation of friction coupling during mining mine operation. Slip lines in mining shaft hoists, Lędziny: Publisher of the Center for Research and Underground Mining Surveillance, 2001.

[4] A. Carbogno. Selected problems regarding frictional coupling between the steel wire and the wheel liner, Gliwice: Silesian University of Technology, 2006.

[5] A. Carbogno A., S. Mateja, J. Pypłacz. Supplementary lubrication of ropes in mining shaft hoists during operations, Lędziny: Publisher of the Center for Research and Underground Mining Surveillance, 2004, pp. 123-135.

[6] A. Carbogno, F. Slanina. Effect of the lubrication of lifting ropes on the safety of mining friction catches, Lędziny: Publisher of the Center for Research and Underground Mining Surveillance, 2006, pp. 136-146.

[7] A. Carbogno, M. Żołnierz, S. Mateja. Research on the coefficient of friction of a rope with surface contact of wires, Lędziny: Publisher of the Center for Research and Underground Mining Surveillance, 2011, pp. 56-62.

[8] A. Carbogno, M. Żołnierz. Test results along with the product evaluation of the wheel lining of hoisting machinery made of BECORIT type K22 and K25SB, Gliwice: Silesian University of Technology, 2008.

[9] A. Carbogno, M. Żołnierz, D. Adamecki. Friction coefficient friction test steel rope - wheel liner, Lędziny: Publisher of the Center for Research and Underground Mining Surveillance, 2007, pp. 127-138. 
[10] H. Goris. Nyrosten N113 preservative for Koepe rope lifts, Nyrosten Company.

[11] J. Hansel. Linings of wheels and rope drums, Kraków: AGH University of Science and Technology, 2012.

[12] Norm DIN 21258: 2007. Lubricants and impregnating agents for traction sheaves - mining ropes. Safety requirements and testing.

[13] J. Pusch. Secondary lubrication of the steel rope the assumption and technical possibilities, Publisher of the Center for Research and Underground Mining Surveillance, 2006, pp. 167-177.

[14] Regulation of the Council of Ministers of April 30, 2004. On the admission of products for use in mining plants.

[15] A. Różok. Examination of the coefficient of friction of the lining of drive wheels of mining hoisting machines, Engineering project, Gliwice: Silesian University of Technology, 2013.

[16] Star LM. Materials of the Elaskon Company. Technologie zur Nachschmierung von Koepe-Förderseilen mit Elaskon III, Berlin: Elaskon Company, 2000.

[17] T. Zmysłowski. Mining hoisting machines. Mechanical part, Katowice - Warszawa: Śląsk Publisher, 2004.

[18] http://www.teufelberger.com

\section{Michał Stawowiak, PhD Eng.}

Marcel Żołnierz, PhD Eng.

Silesian University of Technology,

Faculty of Mining and Geology

Department of Mining Mechanization and Robotisation

ul. Akademicka 2, 44-100 Gliwice, Poland

e-mail: michal.stawowiak@polsl.pl marcel.zolnierz@polsı.pl 